and its ability to effect change, and measures such as the 'Recovery Star' ${ }^{17}$ could be included alongside existing performance indicators in a balanced scorecard using

original papers

calculations demonstrated here.

\section{Implications}

The use of key performance indicators based on routinely collected outcome data promotes a transparent, openbook culture about outcomes. It allows healthcare providers to monitor performance at the same time as giving clinicians the freedom to develop therapeutic programmes that can best deliver real health improvement. More widespread use of similar performance indicators among other providers of secure and forensic services would facilitate benchmarking and further improvement.

\section{Acknowledgements}

We are grateful to all consultants, care coordinators and other clinical staff at St Andrew's Healthcare who have made this work possible by contributing to routine outcome measures collection using HoNOS specialty measures and the HoNOS-secure 'security scale' since 2004.

\section{Declaration of interest}

P.S., L.W. and G.D. are employees of St Andrew's Healthcare.

\section{References}

1 Kaplan RS, Norton DP. The Balanced Scorecard: Translating Strategy into Action. Harvard Business School Press, 1996.

\footnotetext{
3 Sugarman PA, Watkins J. Balancing the scorecard: key performance indicators in a complex healthcare setting. Clinician Manag 2004; 12 : 129-32.

4 Coop CF. Balancing the balanced scorecard for a New Zealand mental health service. Aust Health Rev 2006; 30: 174-80.

5 Slade M, McCrone P, Kuipers E, Leese M, Cahill S, Parabiaghi A, et al. Use of standardised outcome measures in adult mental health services. Randomised controlled trial. BrJ Psychiatry 2006; 189: $330-6$.

6 Cohen A, Eastman N. Needs assessment for mentally disordered offenders: measurement of 'ability to benefit' and outcome. $\mathrm{Br} J$ Psychiatry 2000; 177: 493-8.

7 National Centre for Outcomes Development. Health Outcome Indicators: Severe Mental IIIness. Report of a working group to the Department of Health. NCOD, 1999 (http://nchod.uhce.ox.ac.uk/ mentalillness.pdf).

8 Thomson R, Taber S, Lally J, KazandjianV. UK Quality Indicator Project (UK QIP) and the UK independent health care sector: a new development. Int J Qual Health Care 2004; 16 (suppl 1): i51-6.

9 Dausey DJ, Rosenheck RA, Lehman AF. Preadmission care as a new mental health performance indicator. Psychiatr Serv 2002; 53: 1451-5.

10 Gilbody SM, House AO, SheldonTA. Outcomes research in mental health. Systematic review. $\mathrm{Br}$ Psychiatry 2002; 181: 8-16.
}

11 Phelan M, Slade M, Thornicroft G, Dunn G, Holloway F, WykesT, et al. The Camberwell Assessment of Need: the validity and reliability of an instrument to assess the needs of people with severe mental illness. BrJ Psychiatry 1995; 167 589-95.

12 Wing JK, BeevorAS, Curtis RH, Park SB, Hadden S, Burns A. Health of the Nation Outcome Scales (HoNOS). Research and development. BrJ Psychiatry 1998; 172: 11-8.

13 Pirkis JE, Burgess PM, Kirk PK, Dodson S, CoombsTJ, Williamson MK. A review of the psychometric properties of the Health of the Nation Outcome Scales (HoNOS) family of measures. Health Qual Life Outcomes 2005; 3: 76 .

14 James M. The use of Health of the Nation Outcome Scales (HoNOS) in routine clinical practice by NHS mental health service providers in England: a summary of findings. The Approach 2002; 23: 13-6.

15 Sugarman P, Walker L. HoNOSsecure, Version $2 b$. Royal College of Psychiatrists, 2007 (http:// www.rcpsych.ac.uk/researchand trainingunit/honos/secure.aspx).

16 Dickens G, Sugarman P, Walker L. HoNOS-secure: a reliable outcome measure for users of secure and forensic mental health services. J Forensic Psychiatry Psychol 2007; 18: 507-14.

17 Mental Health Providers Forum BAME project. Mental Health Providers Forum, 2008 (http:// www.mhpf.org.uk/ recoveryStar.asp).

Philip Sugarman Chief Executive and Medical Director, Lorraine Walker Head of Healthcare Governance Department, St Andrew's Healthcare, ${ }^{*}$ Geoff Dickens Research Coordinator and Visiting Lecturer, St Andrew's Academic Centre, King's College London, Institute of Psychiatry, Northampton NN1 5BW, email: gdickens@standrew.co.uk

RAMIN NILFOROOSHAN, RIZKAR AMIN AND JAMES WARNER

\title{
Ethnicity and outcome of appeal after detention under the Mental Health Act 1983
}

\section{AIMS AND METHOD}

There is insufficient research into the relationship between ethnicity and appeals against detention under mental health legislation. We sought to identify rates and success of appeals in different ethnic groups through a retrospective analysis of all detentions under the Mental Health Act 1983 over 1 year.

RESULTS

We found high rates of appeals overall, with substantial differences between ethnic groups (36 (39\%) White British compared with 71 (63\%) Black Caribbean $(P=0.0001)$ and 21
$(68 \%)$ White Irish $(P=0.01)$ individuals (Yates corrected chi-squared)). Success rates on appeal were very low in all groups.

\section{CLINICAL IMPLICATIONS}

There are significant ethnic differences in appeals against detention under the Mental Health Act.
Individuals from different cultures have different patterns of mental illness. ${ }^{1-2}$ Several studies have reported a higher prevalence of severe mental illness, especially schizophrenia, among Black Caribbean people in Britain 
compared with the White population. ${ }^{3-7}$ Other studies reported disproportionate rates for compulsory admissions under both civil and forensic sections of the Mental Health Act 1983 (England and Wales) for Black Caribbean individuals, particularly young men. ${ }^{8-10}$ Black Caribbean individuals seem more likely to have contact with the police and forensic services, ${ }^{11}$ to be treated in locked facilities ${ }^{12}$ and to have had a criminal conviction if they are young and male. ${ }^{13}$ Traumatic feelings arising from detention and coercion experienced by service users and carers may be exacerbated by these inequalities and probably cause mistrust and resistance to intervention, with delayed help-seeking and the necessity for further coercion. ${ }^{14-16}$

One of the most significant changes brought forward in the Mental Health Act 1983 was enhancing individuals' civil rights. For example, appeal against detention was encouraged. There are two types of appeal, the mental health review tribunal (MHRT) and the (hospital) managers appeal (HMA). The MHRT is run by a department of the Lord Chancellors Office. The panel consists of a medical member, a legal member who chairs the panel and a lay member. The HMA is a hearing that includes non-executive members of the trust board who have received appropriate training. Hospital managers are not obliged to hold a hearing each time an appeal is received. As a matter of good practice, individuals should receive application forms for the two different types of appeal along with their 'section papers' and rights (admission pack). There are restrictions on the number of MHRT appeals that can be made during any one period of detention.

A previous study showed the rate of discharge from section after appeal to be $15 \% .{ }^{17}$ In another study, O'Dwyer \& Neville looked at a series of 400 people detained under section 2 . They found an appeal rate of $9 \%$ of eligible individuals; $16 \%$ of appellants were successful. ${ }^{18}$ In this study we explored the association between ethnicity and rates and outcome of appeal against detention under the Mental Health Act 1983.

\section{Method}

This study had the approval of the local research ethics committee. We conducted a retrospective survey of all people detained under civil or forensic sections in a large mental health unit (110 beds) in north-west London over a 1-year period. We included all people who where detained in hospital or had their sections renewed during this period. We excluded people who were admitted under sections that had no right of appeal.

We used the computerised patient administration system to search for all admissions to the unit under the Mental Health Act 1983 during the study period, and also we requested a list of individuals who appealed against section and the outcome of their appeals from the Mental Health Act coordinator. People's self-defined ethnicity (as classified by the UK census) was recorded. Data were analysed by using Statistical Package for Social Sciences (SPSS) version 15 for Windows.

For the purposes of analysis we condensed ethnicity data by combining Asians (Indian, Pakistani, Bangladeshi, Asian other and Arab) together and adding all other groups including mixed ethnicity together as 'others'.

\section{Results}

During the study period, 462 individuals were admitted under civil and forensic sections (270 male, 192 female): 191 under section 2 (28-day order); 220 under section 3 (6-month order; 30 of these were renewed for 6 months or 1 year); and 51 were under various forensic sections.

Two hundred and thirty-two (50.2\%) of these people appealed against their section (147 (54.4\%) male, 85 (44.2\%) female). For those detained under section 2, 51 appealed to the MHRT and 4 to the hospital managers; for those under section 3, 117 appealed to the MHRT and 43 to hospital managers. Sixteen appealed against forensic sections.

Only $4(2 \%)$ people were successful in their appeals (1 White British, 1 Asian, 1 other ethnic group and 1 White other). Further data are shown in Table 1. Compared with White British individuals there were significantly more appeals from Black Caribbean people (Yates' corrected $\chi^{2}=11.9$, d.f. $\left.=1, P=0.0001\right)$ and White Irish people (Yates' corrected $\chi^{2}=7.6$, d.f. $=1, P=0.01$ ). No significant differences emerged comparing White British with Black African or Asian people.

Table 1. Number $(\%)$ of appeals against detention in different ethnic groups (total $n=462$ )

\begin{tabular}{|c|c|c|c|c|c|c|c|}
\hline & \multicolumn{7}{|c|}{$n(\%)$} \\
\hline & $\begin{array}{c}\text { Black British } \\
\text { Caribbean }\end{array}$ & $\begin{array}{l}\text { Black British } \\
\text { African }\end{array}$ & $\begin{array}{l}\text { White } \\
\text { British }\end{array}$ & $\begin{array}{l}\text { White } \\
\text { Irish }\end{array}$ & $\begin{array}{l}\text { White } \\
\text { others }\end{array}$ & Asian & Others \\
\hline Detained & 112 & 63 & 92 & 31 & 15 & 81 & 68 \\
\hline Appealed & $71(63)$ & $22(35)$ & 36 (39) & $21(68)$ & $1(7)$ & $42(52)$ & 39 (57) \\
\hline Not discharged & $31(44)$ & $5(23)$ & $11(31)$ & $8(38)$ & $0(0)$ & $19(45)$ & $11(28)$ \\
\hline $\begin{array}{l}\text { Section discharged before } \\
\text { appeal }\end{array}$ & $24(34)$ & $15(68)$ & $16(44)$ & $12(57)$ & $1(100)$ & $14(33)$ & $13(33)$ \\
\hline Other outcome & $16(22)$ & $2(9)$ & $9(25)$ & $1(5)$ & $0(0)$ & $9(22)$ & 15 (39) \\
\hline
\end{tabular}

a. Transfer out of trust, appeal withdrawn, 
7

original

papers

\section{Discussion}

Our study found that overall, $50 \%$ of individuals appealed against detention with 29\% appealing against section 2 . The success rate of appeal was $2 \%$. This contrasts with the findings of O'Dwyer \& Neville who reported that $9 \%$ appealed against section 2, of whom $17 \%$ were successful. ${ }^{18}$ The increase in appeals found in our study may reflect changing attitudes to appeals by individuals and clinicians, greater understanding of the appeals process or awareness of rights by individuals, carers and advocates. Most people appealed only to the MHRT we were struck by the relative paucity of appeals to hospital managers, especially for those detained under section 2

Although the rates of appeal have increased, the success rate appears to have fallen. This may be as a result of a less liberal approach by both the MHRT and HMA tribunals, but another explanation is that many people are appealing (or being encouraged to appeal) when the chance of a successful appeal is unrealistic. We have observed solicitors and advocates canvassing individuals to submit an appeal which raises questions about the balance between a person's rights to treatment and rights to freedom. Where coercion may operate (for example in encouraging an appeal) this balance is distorted - not in itself a problem if no harm results. However, given that appeals are expensive and often confrontational and counter-therapeutic (patient and consultant are pitched against each other in an adversarial and legalistic milieu neither feels comfortable with) perhaps it is time to overhaul the appeals process. The new Mental Health Act 2007 has not substantially changed the appeals system.

We found substantial differences in the appeal rates between different ethnic groups, with White British and Black African groups appealing less frequently than other major ethnic groups. Several explanations are possible here. It may be because of different attitudes to detention by individuals or carers in different cultures, or a greater desire to encourage appeals in certain ethnic groups by clinicians or advocates. Additionally, it may reflect differences in understanding the appeals process across ethnicities or differences in the appropriateness of original detention (although if this latter point were true one should hopefully expect differences in success rates which were not observed).

This study does have some limitations. It was based in only one unit, albeit in a large one serving an ethnically diverse population. All administrative data may have errors; however, we believe the data are sufficiently robust to draw some conclusions.

Despite much research into ethnic differences in detention rates, we believe there has been insufficient scrutiny of ethnic differences in rates and success of appeals against detention. Further research into how and why people from different backgrounds come to appeal is warranted.

\section{Declaration of interest}

None.

\section{References}

1 Littlewood R. Ethnic minorities and the Mental Health Act. Patterns of explanation. Psychiatr Bull1986; 10: $306-8$.

2 Littlewood R, Lipsedge M. Acute psychotic reactions in Caribbean born patients: two different perceptions of health services by Black Caribbean patients. Psycho Med 1981; 11: 303-18.

3 Erbington PE, HurryJ, Pennant C, Sturt E, Wing J. Epidemiology of mental disorders in Camberwell. Psychol Med 1981: 11: 561-79.

4 Harrison G, Holton A, Nielson D, Owns D. Severe mental disorder in Afro-Caribbean patients: some social, demographic and service factors. Psychol Med 198919 . 683-96.

5 Castle D, Wessely S, Der G, Murray RM. The incidence of operationally defined schizophrenia in Camberwell, 1965-84. Br Psychiatry 1991; 159: 790-4.

6 King M, Cocker E, Leavy G, HoareA, Johnson-Sabine B. Incidence of psychotic illness in London: comparison of ethnic groups. BM 1994; 309: 1115-9.

7 Audini B, Lelliot P. Age, gender and ethnicity of those detained under Part II of Mental Health Act 1983. Br J Psychiatry 2002; 180: 222-6.

8 Harrison G, Owens D, Halton A Milson D, Bhud B. A prospective study of severe mental disorders in Afro-Caribbean patients. Psychol Med 1988; 18: 643-57.

9 Owens D, Harrison G, Bhud D. Ethnic factors in voluntary and

*Ramin Nilforooshan Specialist Registrar Psychiatry, Scutari Clinic, Adamson Centre, StThomas' Hospital, London SE1 7EH, email: ramin.nilforooshan@slam. nhs.uk, Rizkar Amin Consultant Psychiatrist, Park Royal Centre for Mental Health, London, James Warner Consultant and Honorary Senior Lecturer in Older Adult Psychiatry, St Charles Hospital, London compulsive admissions. Psychol Med 1991; 21: 185-96.

10 Szmukler G, Bird AS, Button EJ. Compulsory admission in a London borough: I. Social and clinical features on the follow-up. Psychol Med 1981; 11: 617-36.

11 Moodley P,Thornicroft G. Ethnic group and compulsory detention. Med Sci Law1988; 28: $324-8$.

12 McGovern D, Cope R. Second generation of Afro-Caribbeans and young whites with a first admission diagnosis of schizophrenia. Psychiatry Psychiatr Epidemiol 1991; 26: $95-9$

13 Wessely SC, Castle D, Douglas AJ, Taylor PJ. The criminal careers of incident cases of schizophrenia Psychol Med 1994; 24: 483-502.

14 Singh SP, BurnsT. Race and mental illness: there is more to race than racism. BMJ 2006, 333: 648-51.

15 Morgan C, Mallet R, Hutchinson G, Leff J. Negative pathways to psychiatric care and ethnicity: the bridge between social science and psychiatry. Soc Sci Med 2004; 58 $739-52$

16 Singh SP Greenwood N White $S$ Churchill R. Ethnicity and the Mental Health Act 1983. BrJ Psychiatry 2007; 191: 99-105.

17 Crimlisk H, Phelan M. Mental health review tribunals. Time for a change? BrJ Psychiatry1996; 169: 678-81.

18 O'Dwyer J, Neville P. Appeals against Section 2 of the Mental Health Act 1983. Psychiatr Bull 1991; 15: 225-6. 